\title{
Associations Between Meeting the 24-Hour Movement Guidelines and Cardiometabolic Risk in Young Children
}

\author{
Leigh M. Vanderloo \\ Hospital for Sick Children Research \\ Institute
}

\author{
Mark S. Tremblay \\ CHEO Research Institute
}

\author{
Jonathan L. Maguire and \\ Charles D.G. Keown-Stoneman \\ St. Michael's Hospital and University of \\ Toronto
}

\author{
Laura N. Anderson \\ McMaster University
}

\author{
Patricia C. Parkin and Cornelia \\ M. Borkhoff \\ Hospital for Sick Children Research \\ Institute and University of Toronto \\ Catherine S. Birken \\ Hospital for Sick Children Research \\ Institute and University of Toronto
}

\section{on behalf of the TARGet Kids! Collaboration}

\begin{abstract}
Introduction: The authors aimed to examine the association between meeting the integrative movement behavior guidelines (physical activity, screen viewing, and sleep) and cardiometabolic risk (CMR) factors in young children. Methods: In this crosssectional study, physical activity, screen viewing, and sleep were assessed using parent-reported data. The 24-Hour Movement Guidelines for the Early Years ( $0-4$ y) were defined as 180 minutes of physical activity/day (of which $\geq 60$ min should be moderate-to-vigorous intensity), $\leq 1$ hour of screen viewing/day, and 10 to 13 hours of sleep/night. Waist circumference, glucose, high-density lipoprotein cholesterol, triglycerides, and systolic blood pressure were measured in a clinical setting by trained staff. A total CMR score and individual CMR factors served as primary and secondary outcomes, respectively. Results: Of the 767 participants (3-4 y), 26.4\% met none of the guideline's recommendations, whereas $41.3 \%, 33.1 \%$, and $10.6 \%$ of the sample met 1,2 , or all 3 recommendations, respectively. The number of recommendations met was not associated with the total CMR score or individual CMR factors $(P>.05)$, with the exceptions of high-density lipoprotein (odds ratio $=1.61 ; 95 \%$ confidence interval, 1.11 to $2.33 ; P=.01$ ). Conclusion: Meeting the 24-Hour Movement Guidelines in early childhood was not associated with overall CMR, but was associated with favorable cholesterol outcomes.
\end{abstract}

Keywords: physical activity, sleep, screen viewing, cardiometabolic health, triglycerides, cholesterol, waist circumference, systolic blood pressure

Understanding the health impact of children's movement behaviors over a 24-hour period is of importance and interest to parents, healthcare professionals, and researchers. The Canadian 24-Hour Movement Guidelines for Children and Youth were developed to provide public health guidelines that integrated

Vanderloo, Parkin, Borkhoff, and Birken are with the Child Health Evaluative Sciences, The Hospital for Sick Children Research Institute, Toronto, ON, Canada. Maguire and Keown-Stoneman are with The Applied Health Research Centre, Li Ka Shing Knowledge Institute, St. Michael's Hospital, Toronto, ON, Canada. Maguire, Parkin, and Borkhoff are also with the Dalla Lana School of Public Health, Institute of Health Policy, Management and Evaluation, University of Toronto, Toronto, ON, Canada. Maguire and Parkin are also with the Department of Pediatrics, Faculty of Medicine, University of Toronto, Toronto, ON, Canada. Maguire is also with the Department of Pediatrics, St. Michael's Hospital, Toronto, ON, Canada. Parkin and Borkhoff are also with the Division of Pediatric Medicine, Department of Pediatrics, The Hospital for Sick Children, University of Toronto, Toronto, ON, Canada. Tremblay is with Healthy Active Living and Obesity Research, CHEO Research Institute, Ottawa, ON, Canada. Anderson is with the Department of Health Research Methods, Evidence, and Impact, McMaster University, Hamilton, ON, Canada. Keown-Stoneman and Birken are also with the Dalla Lana School of Public Health, Epidemiology, University of Toronto, Toronto, ON, Canada. Vanderloo (lvande32@uwo.ca) is corresponding author. recommendations for physical activity, sedentary behaviors, and sleep for children aged 5-17 years (52). Children and youth who adhere to these new guidelines have healthier body composition, cardiorespiratory and musculoskeletal fitness, academic achievement and cognition, emotional regulation, prosocial behaviors, cardiovascular and metabolic health, and overall quality of life $(11,13,16,41,46)$.

Extending to the early years, integrative movement behavior guidelines were developed for children aged $0-4$ years to provide guidance regarding healthy physical activity, sedentary behaviors, and sleep hygiene (53). National surveillance data suggest only $13 \%$ of 3- to 4-year-olds in Canada meet all 3 recommendations within the Canadian 24-Hour Movement Guidelines for the Early Years (18). A high proportion of 3- to 4-year-olds in Canada are meeting the physical activity (62\%) and sleep (84\%) recommendations, but only $24 \%$ are meeting the screen time recommendation (18). Various studies have been conducted to explore the relationship between movement behaviors and various health outcomes in the early years, including motor development, psychosocial health, cognitive development, and fitness $(12,17,34,42)$. Missing from our understanding is the association among young children's ability to meet various components of the newly integrated 24- 
Hour Movement Guidelines for the Early Years and their cardiometabolic health.

Cardiometabolic risk (CMR) factors are commonly referred to as characteristics or markers that contribute to cardiovascular disease and the development of type 2 diabetes (8). CMR in childhood may be an important intermediate outcome that can be measured before adolescent and adult disease onset and provide opportunities for prevention $(21,47)$. Among school-aged children, Katzmarzyk and Staiano (32) reported that meeting an increased number of recommendations from the 24-Hour Movement Guidelines for Children and Youth (52) was associated with lower levels of CMR factors (namely, glucose and triglycerides) and obesity among children aged 5-17 years (32). Measures of cardiovascular and metabolic risk, including obesity, dyslipidemia, and elevated glucose and blood pressure, cluster together in young children $(3,6,36,39,42)$. Emerging evidence suggests that CMR is initiated in early life, tracks from childhood into adulthood, and may predict future diabetes and cardiovascular disease $(4,31,33,37)$, but very little is known about movement behaviors and CMR in children under 5 years. Given the above evidence that only a small proportion of young children are meeting the newly adopted 24Hour Movement Guidelines, it is important to determine the effects of this integration of movement behaviors as it relates to CMR. To date, and in part attributed to the challenges and costs of collecting the associated laboratory measures, no investigations have examined the association between integrative movement guidelines and CMR in a population-based sample of children under 5 years.

Movement behaviors that are established early in life may persist across the lifespan $(5,29,35,44,54)$ and affect cardiometabolic health. Building on the previously published work by Katzmarzyk and Staiano (32) with school-aged children, and coupled with the fact that no standardized definition for CMR in young children currently exists, the overarching purpose of this study was to examine the relationship between adherence to Canada's 24-Hour Movement Guidelines for the Early Years (53) and CMR in young children. The primary objective was to examine the association between meeting each individual guideline and a continuous CMR cluster score and individual risk factors. The secondary objective was to examine the association between the number of guideline components met and the odds of improved CMR outcomes.

\section{Methods}

\section{Participants}

As part of a larger study, children $<6$ years of age were recruited to participate in a primary care, practice-based research network in a large city and were followed during scheduled health supervision visits. Of these participants and for the purposes of this study, a cross-sectional subset of children aged 3-4 years were examined. Parents provided written consent for their child's participation in the study, and all materials and protocols received institutional approval from the Hospital for Sick Children and St. Michael's Hospital (REB \#\#1000012436).

\section{Inclusion and Exclusion Criteria}

Children were eligible to participate in the present study if they were between the ages of 3 and 4 years, and had concurrent measures of physical activity, screen use and sleep (exposures), and CMR measures (outcome) available on one or more visits. Children were not included at enrollment if they had any chronic health condition (except for asthma) or severe developmental delay, or if their parents/guardians were unable to complete the consent and questionnaires in English. Children $<3$ years of age were excluded from this study since blood pressure was not collected in this age group.

\section{Movement Behaviors-Exposure Variable}

Data on the participants' physical activity, screen viewing, and sleep were obtained from a standardized parent-reported questionnaire. The questionnaire was supplied to parents at the start of their child's routine health supervision visit, and they were asked to return the completed questionnaire prior to leaving. The parents were instructed to provide open-ended responses reporting how many minutes or hours per weekday and weekend day their child participated in physical activity (any intensity activity and highintensity energetic play), screen use activities, and sleep (on average). From here, total daily averages for each of the individual behaviors were derived by summing the total number of minutes or hours of physical activity/screen use/sleep during the week and over the weekend, for example, (average daily screen use on weekday $\times 5+$ average daily screen use on weekend day $\times 2) / 7$. Meeting the 24-Hour Movement Guidelines (yes/no), inclusive of the individual behavior recommendations (yes/no), was defined as accumulating a minimum of 180 minutes of physical activity per day (of which at least $60 \mathrm{~min}$ is high-intensity energetic play), engaging in a maximum of 1 hour of screen use per day, and getting 10 to 13 hours of sleep per night (53). See Supplementary Table S1 (available online) for specific questions asked to collect information on each of the 3 movement behaviors.

\section{Cardiometabolic Risk Factors-Outcome Variables}

Trained research staff measured waist circumference and systolic blood pressure and collected nonfasting blood samples at each scheduled health supervision visit, using standard clinical procedures (9). Waist circumference was assessed using an anthropometric measuring tape above the child's iliac crest. Mercury sphygmomanometers or automated oscillatory devices were used to measure systolic blood pressure, and appropriate child blood pressure cuff sizes were used. For research purposes, obtaining fasted blood samples from young children in a clinical setting can be challenging; however, previous studies (48), including our team's (2), have shown that the duration of fasting has minimal impact on lipids and glucose in children. Nonfasting blood samples to assess the concentrations of triglycerides, glucose, and high-density lipoproteins were performed at Mount Sinai Laboratory (Toronto, Canada) and analyzed using standard procedures. The time of last drink (except for water) and last snack were recorded by the research staff during the collection of blood to adjust for fasting hours.

Using the Eisenmann protocol $(21,22)$, a continuous total CMR score was derived for each participant. This was achieved by taking the sum of the individual CMR factor $z$ scores from the waist circumference, glucose, (additive inverse) high-density lipoprotein cholesterol (HDL-c), triglycerides, and systolic blood pressure, and then dividing by the square root of 5 . The $z$ scores were calculated using the mean and SD within our population, as has been done in other cohorts $(21,40)$. The inverse of HDL-c was used in the score since higher HDL-c is indicative of a better metabolic profile. A lower total CMR score indicates lower CMR. Similar CMR scores have been used in the literature to assess CMR in children and adolescents $(15,19,20,30,38)$. For the 
individual components, elevated CMR factors were defined as follows, based on age and sex: HDL-c $<1.17 \mathrm{mmol} / \mathrm{L}$ (25), triglycerides $\geq 0.84 \mathrm{mmol} / \mathrm{L}$ (25), systolic blood pressure $\geq 90$ th percentile (stratified by age, sex, and height [26]), or $\geq 90$ th percentile in instances where defined cut-point criteria were absent (glucose and waist circumference). The cut-point for the total CMR dichotomous outcome score was $\geq 90$ th percentile of the total CMR score.

\section{Other Variables-Covariates}

Potential confounding variables were identified a priori based on previous literature and were collected via the aforementioned parent-reported child health questionnaire. These variables included the child's age and sex, maternal education, maternal ethnicity, family history of cardiovascular disease, fasting hours, and annual household income $(14,42,49)$.

\section{Statistical Analyses}

Descriptive characteristics were computed for the exposures, outcome, and covariates. Multiple imputation analysis using 10 imputed datasets was performed to allow the inclusion of subjects with missing covariate data (up to $10 \%$ missing) using the "mice" package in $\mathrm{R}$ (7). The results of the imputed datasets were combined, and the parameter estimates (95\% CIs) for the adjusted pooled models were reported. All variables had levels of missing data under $15 \%$ (24).

For the primary objective, separate general linear models were used to examine the association between meeting each individual component of the guidelines and the continuous outcomes of the total CMR score and individual factors. For the secondary objective, we used multivariable logistic regression to examine the association between each guideline component and elevated CMR, wherein "meeting none of the guidelines" served as the reference group. Age and sex (waist circumference, glucose, HDLc, triglycerides, and systolic blood pressure), fasting time (glucose, HDL-c, and triglycerides), and height (systolic blood pressure) were included as covariates in all models. All analyses were carried out using R (version 3.4.0; https://www.R-project.org).

\section{Results}

The data from a total of 767 children were eligible for analysis (see Figure 1 for flow chart). The descriptive statistics of the sample are presented in Table 1, and all questionnaires were completed by mothers. The average age of the participants was 3.58 years $(\mathrm{SD}=$ $0.81 \mathrm{y}$ ), and $49.3 \%$ were females. The proportion of participants meeting the recommendations of the 24-Hour Movement Guidelines for the Early Years (53) is presented in Table 2. Here, 25.4\% of children met none of the guidelines, whereas $41.3 \%, 23.1 \%$, and $10.2 \%$ of the children met 1,2 , or all 3 guidelines, respectively. Proportions of the guidelines met did not significantly differ based on sex.

The mean CMR cluster score was -0.25 (2.19), ranging from -7.11 to 9.26 . The results of the general linear models are presented in Table 3. No significant associations were identified between meeting 1,2, or 3 of the guidelines and a continuous CMR score or individual CMR factors, except for HDL-c $(P<.01)$. The associations between meeting guideline recommendations and the odds of elevated CMR are presented in Table 4. The results indicate no evidence of an association between meeting the guidelines and dichotomous CMR score or individual CMR factor cutoffs, except for HDL-c. Meeting all 24-hour movement guidelines was associated with reduced odds of unfavorable HDL-c (odds ratio $=1.61$; $95 \%$ confidence interval, 1.11 to $2.33 ; P=.01$ ).

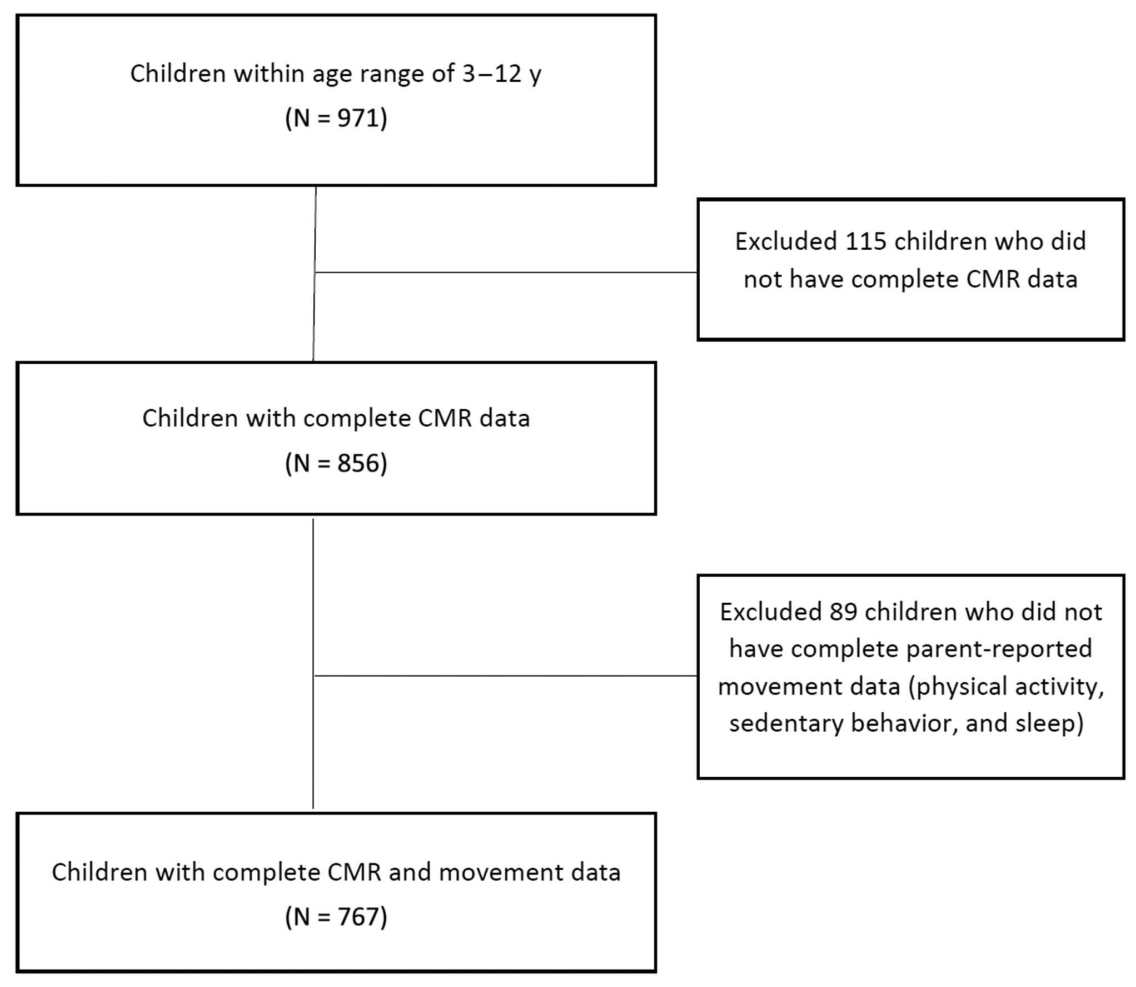

Figure 1 - Participant eligibility flow chart. CMR indicates cardiometabolic risk. 
Table 1 Descriptive Characteristics of Sample

$(\mathrm{n}=767)$

\begin{tabular}{lcc}
\hline Variable & Mean (SD) & $\mathbf{n ~ ( \% )}$ \\
\hline Age, y & $3.58(0.81)$ & \\
Maternal ethnicity & & $68(8.8)$ \\
$\quad$ East Asian & & $494(64.4)$ \\
$\quad$ European & & $59(7.7)$ \\
$\quad$ South/Southeast Asian & & $103(13.4)$ \\
$\quad$ African and Latin American & & $43(5.6)$ \\
$\quad$ Other & & \\
Cardiometabolic risk factors & $57.4(11.2)$ & \\
$\quad$ Waist circumference, cm & $4.1(1.4)$ & \\
$\quad$ Glucose, mmol/L & $1.5(0.76)$ & \\
$\quad \begin{array}{l}\text { High-density lipoprotein } \\
\text { cholesterol, mmol/L }\end{array}$ & \\
$\quad \begin{array}{l}\text { Triglycerides, mmol/L } \\
\text { Systolic blood pressure, mm Hg }\end{array}$ & $91(24.0)$ & \\
\hline
\end{tabular}

\section{Discussion}

In this study, we examined the association between meeting the 24Hour Movement Guidelines for the Early Years (53) and CMR in children 3-4 years of age, wherein only $10 \%$ of the children in the sample met all 3 recommendations outlined in the integrated movement behavior guidelines. These findings are corroborated by Chaput et al (18), who found that $13 \%$ of preschoolers in Canada met all 3 recommendations. Similar trends continue to persist in older children $(10,32,19)$. Roman-Vinas et al (19) found that $14 \%$ of 10 -year-olds in Canada, $2.1 \%$ in the United States, and $7.2 \%$ of 10 -year-old children worldwide from 12 different countries met these guidelines. Furthermore, our results are consistent with published work with older children, whereby similar proportions of children meeting the various components of the integrated movement behaviors were reported (32). Katzmarzyk and Staiano (32) reported that a total of $26.9 \%$ of the sample of children (mean age $=12 \mathrm{y}$ ) met none of the 3 guidelines, whereas $36.4 \%, 28.3 \%$, and $8.4 \%$ of the sample met 1,2 , or all 3 of the guidelines, respectively. Given the published work to date, the prevalence of children meeting the 24-hour integrated behavior guidelines is low (45). To ensure that adequate levels of healthy movement behaviors track throughout the lifespan, efforts to support children

Table 2 Proportion (in Percentages) of Participants Meeting the Individual Recommendations of the 24-Hour Movement Guidelines for the Early Years (0-4 y)

\begin{tabular}{lccc}
\hline Recommendations & Total & Boys & Girls \\
\hline None & 25.4 & 26.0 & 24.8 \\
Physical activity (180 min, including 60 min high-intensity energetic play) & 45.4 & 48.6 & 42.2 \\
Screen viewing & 39.8 & 41.3 & 38.3 \\
Sleep & 51.7 & 49.8 & 53.6 \\
Physical activity + screen viewing & 15.6 & 18.9 & 12.3 \\
Physical activity + sleep & 19.2 & 16.6 & 21.8 \\
Screen viewing + sleep & 22.8 & 21.2 & 24.3 \\
All 3 recommendations & 10.2 & 11.7 & 8.7 \\
\hline
\end{tabular}

Table 3 Adjusted Means (SEs) and Cls for CMR and Meeting Components of the 24-Hour Movement Guidelines per the General Linear

\begin{tabular}{|c|c|c|c|c|c|}
\hline Variable & $\begin{array}{c}\text { None }(n=102) \\
\text { Mean (SE); } 95 \% \mathrm{Cl}\end{array}$ & $\begin{array}{c}1(n=330) \\
\text { Mean (SE); 95\% Cl }\end{array}$ & $\begin{array}{c}2(n=254) \\
\text { Mean (SE); 95\% Cl }\end{array}$ & $\begin{array}{c}3(n=81) \\
\text { Mean (SE); } 95 \% \mathrm{Cl}\end{array}$ & $P$ \\
\hline Total CMR score & $0.8(3.8) ;-6.65$ to 8.25 & $-2.4(3.0) ;-8.28$ to 3.48 & $\begin{array}{c}-1.8(4.6) ; \\
-10.82 \text { to } 7.22\end{array}$ & $\begin{array}{c}-6.6(2.1) \\
-10.72 \text { to }-2.48\end{array}$ & .82 \\
\hline Waist circumference, $\mathrm{cm}$ & $41.3(0.3) ; 40.71$ to 41.89 & $40.0(0.9) ; 38.24$ to 41.76 & $\begin{array}{c}38.7(0.2) ; \\
38.31 \text { to } 39.09\end{array}$ & $\begin{array}{c}36.2(1.4) ; \\
336.61 \text { to } 36.79\end{array}$ & .88 \\
\hline Glucose, $\mathrm{mmol} / \mathrm{L}$ & $4.0(0.2) ; 3.61$ to 4.49 & $3.9(0.9) ; 2.13$ to 5.66 & $3.8(0.3) ; 3.21$ to 4.39 & $3.6(0.3) ; 4.01$ to 4.19 & .12 \\
\hline High-density lipoprotein, $\mathrm{mmol} / \mathrm{L}$ & $\begin{array}{c}46.8(13.7) ; \\
19.95 \text { to } 73.65\end{array}$ & $\begin{array}{c}46.0(10.4) \\
25.62 \text { to } 66.38\end{array}$ & $\begin{array}{c}48.7(12.5) \\
24.30 \text { to } 73.20\end{array}$ & $\begin{array}{c}52.8(11.6) ; \\
30.06 \text { to } 75.54\end{array}$ & .01 \\
\hline Triglycerides, $\mathrm{mmol} / \mathrm{L}$ & $\begin{array}{c}70.8(10.1) \\
51.00 \text { to } 90.60\end{array}$ & 72.4 (9.8); 53.19 to 91.61 & $\begin{array}{c}64.0(12.8) \\
38.91 \text { to } 89.09\end{array}$ & $\begin{array}{c}60.1(10.6) ; \\
39.32 \text { to } 80.88\end{array}$ & .20 \\
\hline $\begin{array}{l}\text { Systolic blood pressure, } \\
\mathrm{mm} \mathrm{Hg}\end{array}$ & $\begin{array}{c}101.8(3.8) \\
109.25 \text { to } 94.35\end{array}$ & $\begin{array}{c}101.3(2.3) \\
96.79 \text { to } 105.81\end{array}$ & $\begin{array}{c}100.9(1.3) \\
98.35 \text { to } 103.45\end{array}$ & $\begin{array}{c}101.5(0.6) ; \\
100.32 \text { to } 102.68\end{array}$ & .07 \\
\hline
\end{tabular}

Abbreviations: CI, confidence interval; CMR, cardiometabolic score; HDL-c, high-density lipoprotein cholesterol. Note: Models were adjusted for age, sex, fasting time (for waist circumference, glucose, HDL-c, and triglycerides), height (systolic blood pressure), maternal education, maternal ethnicity, family history of cardiovascular disease, and annual household income. Bold indicates alpha was set at 0.05 . 
Table 4 Logistic Regression Models for Meeting Specific Movement Guideline Recommendations and the Odds of Elevated CMR

\begin{tabular}{|c|c|c|c|c|c|c|c|}
\hline & & $\begin{array}{c}1 \text { Recommendation } \\
(n=330)\end{array}$ & & $\begin{array}{l}2 \text { Recommendations } \\
(n=254)\end{array}$ & & $\begin{array}{l}3 \text { Recommendations } \\
(\mathrm{n}=81)\end{array}$ & \\
\hline Variable & None $(n=102)$ & OR $(95 \% \mathrm{Cl})$ & $\boldsymbol{P}$ & OR $(95 \% \mathrm{CI})$ & $\boldsymbol{P}$ & OR $(95 \% \mathrm{Cl})$ & $\boldsymbol{P}$ \\
\hline Total CMR score & Ref & $1.48(0.88$ to 3.94$)$ & .08 & $1.94(0.94$ to 3.98$)$ & .07 & $1.31(0.84$ to 2.05$)$ & .24 \\
\hline Waist circumference, $\mathrm{cm}$ & Ref & $1.03(0.52$ to 2.03$)$ & .94 & $1.04(0.63$ to 1.69$)$ & .89 & $1.00(0.51$ to 1.97$)$ & .99 \\
\hline Glucose, $\mathrm{mmol} / \mathrm{L}$ & Ref & $0.92(0.68$ to 1.24$)$ & .58 & $0.94(0.37$ to 2.37$)$ & .89 & $0.82(0.45$ to 1.48$)$ & .51 \\
\hline $\begin{array}{l}\text { High-density lipoprotein } \\
\text { cholesterol, } \mathrm{mmol} / \mathrm{L}\end{array}$ & Ref & $0.7(0.40$ to 1.27$)$ & .25 & 0.77 (0.34 to 1.77$)$ & .54 & 1.61 (1.11 to 2.33$)$ & .01 \\
\hline Triglycerides, $\mathrm{mmol} / \mathrm{L}$ & Ref & $1.12(0.92$ to 1.36$)$ & .27 & 1.03 (0.68 to 1.56$)$ & .88 & $0.78(0.92$ to 1.36$)$ & .27 \\
\hline Systolic blood pressure, $\mathrm{mm} \mathrm{Hg}$ & Ref & $4.19(0.97$ to 18.11$)$ & .06 & $1.96(0.75$ to 5.09$)$ & .17 & 1.89 (0.88 to 4.08$)$ & .10 \\
\hline
\end{tabular}

Abbreviations: CI, confidence interval; CMR, cardiometabolic risk; HDL-c, high-density lipoprotein cholesterol; OR, odds ratio. Note: Models were adjusted for age, sex, fasting time (for waist circumference, glucose, HDL-c, and triglycerides), height (systolic blood pressure), maternal education, maternal ethnicity, family history of cardiovascular disease, and annual household income. High risk cutoffs: HDL-c $<1.17 \mathrm{mmol} / \mathrm{L}$ (25), triglycerides $\geq 0.84 \mathrm{mmol} / \mathrm{L}$ ( 25 ), systolic blood pressure $\geq 90$ th percentile (on the basis of age, sex, and height tables [26]), or $\geq 90$ th percentile in instances where defined cut-point criteria were absent (glucose and waist circumference). Bold indicates alpha was set at 0.05 .

in developing strong habits at a very young age should remain a priority, particularly when such lifestyle behaviors are more malleable (28).

We identified a significant association between meeting all guidelines and favorable HDL-c outcomes. Similarly, Ekelund et al (23) examined the association between moderate to vigorous physical activity, sedentary time, and CMR in a total of 2781 (4- to 8-yearold) children and found that MVPA was associated with significantly higher values of HDL-c across tertiles for sedentary time. Likewise, Carson et al ( $n=4157$; 6-17 y [10]) found that meeting more components of the guidelines was associated with higher levels of HDL-c and more favorable blood pressure. It is relatively known that, among children, levels of HDL-c tend to be elevated with increased physical activity (50); therefore, these findings may suggest that this particular biomarker is more sensitive to behaviors at this young age. Conversely, triglycerides and low-density lipoprotein cholesterol are less responsive and may require a longer exposure load before variability can be detected (50), thus partially explaining the lack of findings in this young age group. As HDL-c has been shown to track from late childhood into adulthood $(1,27)$, it remains an important marker of cardiometabolic health, which warrants additional focus.

Unlike the work conducted by Katzmarzyk and Staiano (32), which reported significant associations between the number of guidelines met and triglycerides and glucose among a school-age sample, we did not recount any additional significant associations with the remaining individual CMR markers. The absence of an association between meeting the 24-Hour Movement Guidelines and the remaining individual CMR factors among young children could be attributed to the small number of children in this age group being at high CMR or, perhaps in this context, it is too early to detect a true association between the variables being explored. The later notion may be further supported by findings from the nationally representative Canadian Health Measures Survey (cycle 2: 2009-2011 and cycle 3: 2012-2013), which demonstrated time spent in each movement behavior was not associated with waist circumference or BMI $z$ scores in predominantly term-born preschool-aged children (11). Nonetheless, given the mixed or null findings regarding children's CMR and integrative movement behaviors, additional confirmatory studies are required, and young children should still be encouraged to engage in healthy levels of daily physical activity, screen use, and sleep for overall health and development.

\section{Strengths and Limitations}

The large sample size of young children and the clinical and laboratory measurements are noteworthy strengths of this study. The main limitation of this study was the use of self-reported data to assess the integrated movement behaviors, which can be limited by recall and bias. However, the exposure variables examined in this study were taken from a validated national survey (51). The crosssectional design of this study is also a limitation, as it precludes the possibility of making inferences regarding cause and effect, and there may be unmeasured confounding. Because only mothers completed the study questionnaires, we were only able to include information on maternal education and ethnicity. There is currently no standardized definition for defining CMR in young children, and multiple approaches exist to calculate related scores $(21,47)$. However, this paper utilized the Eisenmann scoring approach (21), which has demonstrated strong agreement and construct validity in slightly older children (7-9 y [22]).

\section{Conclusion}

Only a small percentage of young children in this sample met all 3 recommendations of the 24-Hour Movement Guidelines for the Early Years. Apart from HDL-c, evidence of an association between meeting components of the 24-Hour Movement Guidelines (53) and overall CMR score or other individual CMR factors was not identified. It is possible that the exposure-meeting the guidelines - may be too crude of a measure, and the next steps may include exploring each of the movement behaviors continuously and examining the outcomes individually. To promote healthy development and prevent early disease onset, future interventions should consider strategies that simultaneously improve physical activity, screen use, and sleep while examining their association with CMR outcomes throughout childhood to observe whether the findings from this paper persist.

\section{Acknowledgments}

The funding agencies had no role in the design and conduct of the study, the collection/analysis, interpretation of the data, or the preparation and approval of the manuscript. The authors have no conflict of interest to declare. The PCP reports receiving the following grants unrelated to this 
study: a grant from the Canadian Institutes of Health Research (FRN \# 115059) for an ongoing investigator-initiated trial of iron deficiency in young children, for which Mead Johnson Nutrition provides nonfinancial support (Fer-In-Sol ${ }^{\circledR}$ liquid iron supplement; 2011-2017); and peerreviewed grants for completed investigator-initiated studies from Danone Institute of Canada (2002-2004 and 2006-2009), Dairy Farmers of Ontario (2008-2010). J.L.M. received an unrestricted research grant for a completed investigator-initiated study from the Dairy Farmers of Canada (2011-2012), and Ddrops provided nonfinancial support (vitamin D supplements) for an investigator-initiated study on vitamin D and respiratory tract infections (2011-2015). C.M.B. reports previously receiving a grant for a completed investigator-initiated study from the SickKids Center for Health Active Kids (CHAK; 2015-2016), involving the development and validation of a risk stratification tool to identify young asymptomatic children at risk for iron deficiency. These agencies had no role in the design, collection, analyses, or interpretation of the results of this study or in the preparation, review, or approval of the manuscript. L.M.V. and C.S.B. conceptualized the study. L.M.V. and C.D.G.K. were responsible for the data cleaning/data analysis. L.M.V. wrote the initial draft of the manuscript. All authors provided feedback on the drafts and approved the final manuscript. This study was supported by the Canadian Institutes of Health Research (CIHR), The Hospital for Sick Children Foundation (with a grant to the Paediatric Outcomes Research Team), and St. Michael's Hospital Foundation. L.M.V. was supported by a CIHR Fellowship Award. The authors would like to thank the child participants and their families for their participation in this study, as well as to all clinicians who are currently involved in the TARGet Kids! practicebased research network.

*TARGet Kids! Collaborators-Co-Leads: Catherine S. Birken, Jonathon L. Maguire; Advisory Committee: Ronald Cohn, Eddy Lau, Andreas Laupacis, Patricia C. Parkin, Michael Salter, Peter Szatmari, Shannon Weir; Science Review and Management Committees: Laura N. Anderson, Cornelia M. Borkhoff, Charles Keown-Stoneman, Christine Kowal, Dalah Mason; Site Investigators: Murtala Abdurrahman, Kelly Anderson, Gordon Arbess, Jillian Baker, Tony Barozzino, Sylvie Bergeron, Dimple Bhagat, Gary Bloch, Joey Bonifacio, Ashna Bowry, Caroline Calpin, Douglas Campbell, Sohail Cheema, Elaine Cheng, Brian Chisamore, Evelyn Constantin, Karoon Danayan, Paul Das, Mary Beth Derocher, Anh Do, Kathleen Doukas, Anne Egger, Allison Farber, Amy Freedman, Sloane Freeman, Sharon Gazeley, Charlie Guiang, Dan Ha, Curtis Handford, Laura Hanson, Leah Harrington, Sheila Jacobson, Lukasz Jagiello, Gwen Jansz, Paul Kadar, Florence Kim, Tara Kiran, Holly Knowles, Bruce Kwok, Sheila Lakhoo, Margarita Lam-Antoniades, Eddy Lau, Denis Leduc, Fok-Han Leung, Alan Li, Patricia Li, Jessica Malach, Roy Male, Vashti Mascoll, Aleks Meret, Elise Mok, Rosemary Moodie, Maya Nader, Katherine Nash, Sharon Naymark, James Owen, Michael Peer, Kifi Pena, Marty Perlmutar, Navindra Persaud, Andrew Pinto, Michelle Porepa, Vikky Qi, Nasreen Ramji, Noor Ramji, Danyaal Raza, Alana Rosenthal, Katherine Rouleau, Caroline Ruderman, Janet Saunderson, Vanna Schiralli, Michael Sgro, Hafiz Shuja, Susan Shepherd, Barbara Smiltnieks, Cinntha Srikanthan, Carolyn Taylor, Stephen Treherne, Suzanne Turner, Fatima Uddin, Meta van den Heuvel, Joanne Vaughan, Thea Weisdorf, Sheila Wijayasinghe, Peter Wong, John Yaremko, Ethel Ying, Elizabeth Young, Michael Zajdman; Research Team: Farnaz Bazeghi, Marivic Bustos, Charmaine Camacho, Dharma Dalwadi, Christine Koroshegyi, Tarandeep Malhi, Sharon Thadani, Julia Thompson, Laurie Thompson; Project Team: Mary Aglipay, Imaan Bayoumi, Sarah Carsley, Katherine Cost, Anne Fuller, Laura Kinlin, Jessica Omand, Shelley Vanderhout, Leigh Vanderloo; Applied Health Research Centre: Christopher Allen, Bryan Boodhoo, Olivia Chan, David W.H. Dai, Judith Hall, Peter Juni, Gerald Lebovic, Karen Pope, Kevin Thorpe; Mount Sinai Services Laboratory: Rita Kandel, Michelle Rodrigues.

\section{References}

1. Albaum JM, Carsley S, Chen Y, et al. Persistent high non-highdensity lipoprotein cholesterol in early childhood: a latent class growth model analysis. J Pediatr. 2017;191:152-7. PubMed ID: 29173300 doi:10.1016/j.jpeds.2017.08.079

2. Anderson LN, Lebovic G, Hamilton J, et al. Body mass index, waist circumference, and the clustering of cardiometabolic risk factors in early childhood. Paediatr Perinat Epidemiol. 2016;30(2):160-70. PubMed ID: 26645704 doi:10.1111/ppe.12268

3. Anderson LN, Maguire JL, Lebovic G, et al. Duration of fasting, serum lipids, and metabolic profile in early childhood. J Pediatr. 2017;180:47-52.e1. PubMed ID: 27742126 doi:10.1016/j.jpeds. 2016.09.005

4. Berenson GS, Srinivasan SR, Bao W, Newman WP, Tracy RE, Wattigney WA. Association between multiple cardiovascular risk factors and atherosclerosis in children and young adults. The Bogalusa heart study. N Engl J Med. 1998;338(23):1650-6. PubMed ID: 9614255 doi:10.1056/NEJM199806043382302

5. Biddle SJH, Pearson N, Ross GM, Braithwaite R. Tracking of sedentary behaviours of young people: a systematic review. Prev Med (Baltim). 2010;51(5):345-51. PubMed ID: 20682330 doi:10. 1016/j.ypmed.2010.07.018

6. Brambilla P, Lissau I, Flodmark CE, et al. Metabolic risk-factor clustering estimation in children: to draw a line across pediatric metabolic syndrome. Int J Obes. 2007;31(4):591-600. PubMed ID: 17384660 doi:10.1038/sj.ijo.0803581

7. Buuren SV, Groothuis-Oudshoorn K. MICE: multivariate imputation by chained equations in R. J Stat Softw. 2011;45(3):1-67. doi:10. 18637/jss.v045.i03

8. Cardiometabolic Risk Working Group: Executive Committee, Leiter LA, Fitchett DH, et al. Cardiometabolic risk in Canada: a detailed analysis and position paper by the cardiometabolic risk working group. Can J Cardiol. 2011;27(2):e1-e33. PubMed ID: 21459257 doi:10.1016/j.cjca.2010.12.054

9. Carsley S, Borkhoff CM, Maguire JL, et al. Cohort profile: the applied research group for kids (TARGet Kids!). Int J Epidemiol. 2015;44(3):776-88. PubMed ID: 24982016 doi:10.1093/ije/ dyu 123

10. Carson V, Chaput J-P, Janssen I, Tremblay MS. Health associations with meeting new 24-hour movement guidelines for Canadian children and youth. Prev Med. 2017;95:7-13. PubMed ID: 27923668 doi:10.1016/j.ypmed.2016.12.005

11. Carson V, Hunter S, Kuzik N, et al. Systematic review of physical activity and cognitive development in early childhood. J Sci Med Sport. 2016;19(7):573-8. PubMed ID: 26197943 doi:10.1016/j. jsams.2015.07.011

12. Carson V, Hunter S, Kuzik N, et al. Systematic review of sedentary behaviour and health indicators in school-aged children and youth: an update. Appl Physiol Nutr Metab. 2016;41(6):S240-65. PubMed ID: 27306432 doi:10.1139/apnm-2015-0630

13. Carson V, Lee E-Y, Hewitt L, et al. Systematic review of the relationships between physical activity and health indicators in the early years (0-4 years). BMC Public Health. 2017;17 Suppl 5:854. PubMed ID: 29219090 doi:10.1186/s12889-017-4860-0

14. Carson V, Tremblay MS, Chaput JP, Chastin SF. Associations between sleep duration, sedentary time, physical activity, and health indicators among Canadian children and youth using compositional analyses. Appl Physiol Nutr Metab. 2016;41(6):S294-S302. PubMed ID: 27306435 doi:10.1139/apnm-2016-0026

15. Cespedes EM, Rifas-Shiman SL, Redline S, Gillman MW, Peña MM, Taveras EM. Longitudinal associations of sleep curtailment with 
metabolic risk in mid-childhood. Obesity. 2014;22(12):2586-92. PubMed ID: 25234485 doi:10.1002/oby.20894

16. Chaput JP, Colley RC, Aubert S, et al. Proportion of preschool-aged children meeting the Canadian 24-hour movement guidelines and associations with adiposity: results from the Canadian health measures survey. BMC Public Health. 2017;17 Suppl 5:147-54. PubMed ID: 29219075 doi:10.1186/s12889-017-4854-y

17. Chaput J-P, Gray CE, Poitras VJ, Carson V, Gruber R, Olds T. Systematic review of the relationships between sleep duration and health indicators in school-aged children and youth. Appl Physiol Nutr Metab. 2016;41(6):S266-82. PubMed ID: 27306433 doi:10. 1139/apnm-2015-0627

18. Chaput J-P, Gray CE, Poitras VJ, et al. Systematic review of the relationships between sleep duration and health indicators in the early years (0-4 years). BMC Public Health. 2017;17 Suppl 5:855. PubMed ID: 29219078 doi:10.1186/s12889-017-4850-2

19. Roman-Vinas B, Chaput JP, Katzmarzyk PT, et al. Proportion of children meeting recommendations for 24-hour movement guidelines and associations with adiposity in a 12-country study. Int J Behav Nutr Phys Act. 2016;13:123.

20. Eisenmann JC. On the use of a continuous metabolic syndrome score in pediatric research. Cardiovasc Diabetol. 2008;7(1):17. PubMed ID: 18534019 doi:10.1186/1475-2840-7-17

21. Eisenmann JC, Laurson KR, DuBose KD, Smith BK, Donnelly JE. Construct validity of a continuous metabolic syndrome score in children. Diabetol Metab Syndr. 2010;2(1):8. PubMed ID: 20181030 doi:10.1186/1758-5996-2-8

22. Eisenmann JC, Wickel EE, Welk GJ, Blair SN. Relationship between adolescent fitness and fatness and cardiovascular disease risk factors in adulthood: the aerobics center longitudinal study (ACLS). Am Heart J. 2005;149(1):46-53. PubMed ID: 15660033 doi:10.1016/j. ahj.2004.07.016

23. Ekelund U, Luan J, Sherar LB, Esliger DW, Griew P, Cooper A. Association of moderate to vigorous physical activity and sedentary time with cardiometabolic risk factors in children and adolescents. JAMA. 2012;307(7):704-12. PubMed ID: 22337681 doi:10.1001/ jama.2012.156

24. Enders CK. Using the expectation maximization algorithm to estimate coefficient alpha for scales with item-level missing data. Psychol Methods. 2003;8(3):322-37. PubMed ID: 14596494 doi:10.1037/ 1082-989X.8.3.322

25. Expert Panel on Integrated Guidelines for Cardiovascular Health and Risk Reduction in Children and Adolescents. Expert panel on integrated guidelines for cardiovascular health and risk reduction in children and adolescents: summary report. Pediatrics. 2011;128 Suppl 5:S213-56. PubMed ID: 22084329 doi:10.1542/peds.2009$2107 \mathrm{c}$

26. Flynn JT, Kaelber DC, Baker-Smith CM, et al. Expert panel on integrated guidelines for cardiovascular health and risk reduction in children and adolescents: summary report. Pediatrics. 2017;140(3): e20171904. PubMed ID: 28827377 doi:10.1542/peds.2017-1904

27. Friedman LA, Morrison JA, Daniels SR, McCarthy WF, Sprecher DL. Sensitivity and specificity of pediatric lipid determinations for adult lipid status: findings from the princeton lipid research clinics prevalence program follow-up study. Pediatrics. 2006;118(1):16572. PubMed ID: 16818562 doi:10.1542/peds.2005-2968

28. Goldfield GS, Harvey A, Grattan K, Adamo KB. Physical activity promotion in the preschool years: a critical period to intervene. Int J Environ Res Public Health. 2012;9(4):1326-42. PubMed ID: 22690196 doi:10.3390/ijerph9041326

29. Hayes G, Dowd KP, MacDonncha C, Donnelly AE. Tracking of physical activity and sedentary behavior from adolescence to young adulthood: a systematic literature review. J Adolesc Heal. 2019;65(4): 446-54. PubMed ID: 31248803 doi:10.1016/j.jadohealth.2019. 03.013

30. Hjorth MF, Chaput JP, Damsgaard CT, et al. Low physical activity level and short sleep duration are associated with an increased cardiometabolic risk profile: a longitudinal study in 8-11 year old Danish children. PLoS One. 2014;9(8):e104677. PubMed ID: 25102157 doi:10.1371/journal.pone.0104677

31. Juonala M, Viikari JSA, Raitakari OT. Main findings from the prospective cardiovascular risk in young Finns study. Curr Opin Lipidol. 2013;24(1):57-64. PubMed ID: 23069987 doi:10.1097/ MOL.0b013e32835a7ed4

32. Katzmarzyk P, Staino A. Relationship between meeting 24-hour movement guidelines and cardiometabolic risk factors in children. J Phys Act Health. 2017;14(10):779-84. PubMed ID: 28556685 doi:10.1123/jpah.2017-0090

33. Kelly AS, Steinberger J, Jacobs DR, Hong C-P, Moran A, Sinaiko AR. Predicting cardiovascular risk in young adulthood from the metabolic syndrome, its component risk factors, and a cluster score in childhood. Int J Pediatr Obes. 2011;6(2):e283-9. PubMed ID: 21070100 doi: $10.3109 / 17477166.2010 .528765$

34. Kuzik N, Poitras VJ, Tremblay MS, Lee E-Y, Hunter S, Carson V. Systematic review of the relationships between combinations of movement behaviors and health indicators in the early years (0 to 4 years). BMC Public Health. 2017;17 Suppl 5:849. PubMed ID: 29219071 doi:10.1186/s12889-017-4851-1

35. Malina RM. Physical activity and fitness: pathways from childhood to adulthood. Am J Hum Biol. 2001;13(2):162-72. PubMed ID: 11460860 doi:10.1002/1520-6300(200102/03)13:2<162::AID-AJHB 1025>3.0.CO;2-T

36. Morrison KM, Anand SS, Yusuf S, et al. Maternal and pregnancy related predictors of cardiometabolic traits in newborns. PLoS One. 2013;8(2):e55815. PubMed ID: 23418462 doi:10.1371/journal.pone. 0055815

37. National Heart, Lung and Blood Institute. Expert panel on integrated guidelines for cardiovascular health and risk reduction in children and adolescents. Pediatrics. 2011;128(Suppl 5):S213-S256.

38. Okosun IS, Boltri JM, Lyn R, Davis-Smith M. Continuous metabolic syndrome risk score, body mass index percentile, and leisure time physical activity in American children. J Clin Hyoertens. 2010;12(8): 636-44. PubMed ID: 20695944 doi:10.1111/j.1751-7176.2010. 00338.x

39. Pietrobelli A, Malavolti M, Battistini NC, Fuiano N. Metabolic syndrome: a child is not a small adult. Int J Pediatr Obes. 2008;3 Suppl 1:67-71. PubMed ID: 18278635 doi:10.1080/17477160801 897133

40. Plumptre L, Anderson LN, Chen Y, et al. Longitudinal analysis of sleep duration and cardiometabolic risk in young children. Child Obes. 2017;13(4):291-9. PubMed ID: 30433827 doi:10.1089/chi. 2016.0279

41. Poitras VJ, Gray CE, Borghese MM, et al. Systematic review of the relationships between objectively measured physical activity and health indicators in school-aged children and youth. Appl Physiol Nutr Metab. 2016;41(6) Suppl 3:S197-239. PubMed ID: 27306431 doi:10.1139/apnm-2015-0663

42. Poitras VJ, Gray CE, Janssen X, et al. Systematic review of the relationships between sedentary behaviour and health indicators in the early years (0-4 years). BMC Public Health. 2017;17 Suppl 5:868. PubMed ID: 29219092 doi:10.1186/s12889-0174849-8

43. Retnakaran R, Zinman B, Connelly PW, Harris SB, Hanley A. Nontraditional cardiovascular risk factors in pediatric metabolic 
syndrome. J Pediatr. 2006;148(2):176-82. PubMed ID: 16492425 doi:10.1016/j.jpeds.2005.08.025

44. Rhodes RE, Janssen I, Bredin SSD, Warburton DER, Bauman A. Physical activity: health impact, prevalence, correlates and interventions. Psychol Heal. 2017;32(8):942-75. PubMed ID: 28554222 doi:10.1080/08870446.2017.1325486

45. Rollo S, Antsygina O, Tremblay M. The whole day matters: understanding 24-hour movement guideline adherence and relationships with health indicators across the lifespan. J Sport Heal Sci. 2020; 9(6):493-510. PubMed ID: 32711156 doi:10.1016/j.jshs.2020. 07.004

46. Saunders TJ, Gray CE, Poitras VJ, et al. Combinations of physical activity, sedentary behaviour and sleep: relationships with health indicators in school-aged children and youth. Appl Physiol Nutr Metab. 2016;41(6):S283-93. PubMed ID: 27306434 doi:10.1139/ apnm-2015-0626

47. Sovio U, Skow A, Falconer C, Park MH, Viner RM, Kinra S. Improving prediction algorithms for cardiometabolic risk in children and adolescents. J Obes. 2013;2013:684782. PubMed ID: 23862055 doi:10.1155/2013/684782

48. Steiner MJ, Skinner AC, Perrin EM. Fasting might not be necessary before lipid screening: a nationally representative cross-sectional study. Pediatrics. 2011;128:463-70. PubMed ID: 21807697 doi:10. 1542/peds.2011-0844
49. Timmons BW, LeBlanc AG, Carson V, Connor GS, Dillman C, Janssen I. Systematic review of physical activity and health in the early years (aged 0-4 years). Appl Physiol Nutr Metab. 2012;37(4): 773-92. PubMed ID: 22765840 doi:10.1139/h2012-070

50. Tolfrey K, Jones AM, Campbell IG. The effect of aerobic exercise training on the lipid-lipoprotein profile of children and adolescents. Sport Med. 2000;29(2):99-112. PubMed ID: 10701713 doi:10.2165/ 00007256-200029020-00003

51. Tremblay M, Wolfson M, Gorber SC. Canadian health measures survey: rationale, background and overview. Health Rep. 2007; 18 Suppl:7-20. PubMed ID: 18210866

52. Tremblay MS, Carson V, Chaput J-P, et al. Canadian 24-hour movement guidelines for children and youth: an integration of physical activity, sedentary behaviour, and sleep. Appl Physiol Nutr Metab. 2016;41(6) Suppl 3:S311-27. PubMed ID: 27306437 doi:10.1139/apnm-2016-0151

53. Tremblay MS, Chaput J-P, Adamo KB, et al. Canadian 24-hour movement guidelines for the early years $(0-4$ years): an integration of physical activity, sedentary behaviour, and sleep. BMC Public Health. 2017;17(S5):874. PubMed ID: 29219102 doi:10.1186/ s12889-017-4859-6

54. Williamson AA, Mindell JA, Hiscock H, Quach J. Sleep problem trajectories and cumulative socio-ecological risks: birth to school-age. J Pediatr. 2019;215:229-37.e4. PubMed ID: 31564429 doi:10.1016/ j.jpeds.2019.07.055 